\title{
OFF-DESIGN MODELLING OF ORC TURBINES FOR GEOTHERMAL APPLICATION
}

\author{
Pietro Ungar ${ }^{1,{ }^{*}}$, Zekeriya Özcan ${ }^{2}$, Giampaolo Manfrida $^{3}, \ddot{O ̈}_{z}$ ür Ekici ${ }^{4}$, Lorenzo Talluri ${ }^{5}$ \\ 1,3,5 Università degli Studi di Firenze, Dipartimento di Ingegneria Industriale, Firenze, Italy \\ 2,4 Department of Mechanical Engineering, Hacettepe University, Beytepe, Ankara, Turkey
}

\begin{abstract}
In this study, turbine modelling of a geothermal sourced organic Rankine cycle (ORC) power plant is aimed. Thermodynamic model of the plant is constructed with the help of design and off-design plant data from an existing two-cycle power plant in southwestern Anatolia. Utilizing statistical analysis tools such as maximum likelihood estimation and probability distribution, plant variables are obtained within their standard deviations. Stodola curves and probability calculations demonstrate that both turbines are most likely to have two stages. Average losses are 2.3 MW and 1.2 MW from Turbine-I and Turbine-II respectively throughout the different seasons. After the determination of losses, overall turbine efficiencies demonstrate a reverse trend with increasing reduced mass flow rate. This may be associated with the increased choking of the turbine. Correlations estimate rather fixed efficiency values at off-design conditions ( $84 \%$ for Turbine-I and $77 \%$ for Turbine-II); that is an expected outcome since these correlations are influenced mainly by the design isentropic efficiency, which is a constant value. On the other hand, these correlations are most likely to be proposed for non-choking conditions which are invalid for off-design conditions of existing ORC turbines. Datapoint dispersion in Turbine-II does not demonstrate a strong correlation with physical constraints such as -pressure ratio and reduced mass flow rate- as it does for Turbine-I; this phenomenon may need further attention for future work.
\end{abstract}

Keywords: Turbine Curve Modelling, ORC, Statistical Model, Plant Variables.

\section{Introduction}

Power extraction from geothermal sources has been a subject of attention since the early twentieth century due to the increasing demand of electricity. Beginning from the very first dry steam application in Larderello [1] in 1911, as of 2019, worldwide installed geothermal plant capacity reached around 14,900 MW [2]. Throughout the years, power generation methodologies from a geothermal source are diversified parallel to the technologic innovations. Depending on the source temperature, flash steam and binary steam methods are other most common methods for geothermal applications. Typical application range for flash steam includes temperatures beyond $180{ }^{\circ} \mathrm{C}$, where hot brine flows through the well accompanied by a pressure drop that causes vaporization of the geothermal brine. Finally, steam is separated from liquid water and cycled for power generation purposes, where liquid

* Corresponding author: pietro.ungar@unifi.it 
water (and residual condensed steam) is pumped back to the source [3]. On the other hand, binary steam targets low and moderate source temperature ranges (i.e. $100-180{ }^{\circ} \mathrm{C}$ ). In this method, enthalpy of extracted brine is transferred in heat exchangers to a second medium with a lower boiling point, which is cycled in closed systems. Based on this principle, state of art demonstrates two common cyclic systems namely- organic Rankine cycle (ORC) and Kalina cycle (KC)-. Kalina cycle operates with ammonia-water mixture as working fluid [4] while ORC systems use organic based working fluids as the term implies [5]. Despite the long history of Rankine principles and utilization of organic fluid instead of water is not a novel idea, there are still challenges in ORC applications to be dealt with. DiPippo [6] discussed thermal efficiency ranges of ORC geothermal plants to define optimal design characteristics as a function of brine properties such as mass flow rate or extraction temperature. Working fluid selection is an important topic, since it is the working fluid which determines the thermal compatibility in heat exchangers and expanders [7-9]. Turbine modelling at off-design conditions is another important topic in order to achieve optimal work output from the plant. Ellipse law of Stodola [10] can be considered as the pioneer in context of modelling off-design multistage turbine pressures. In recent years there also are many studies focusing on that issue. Gabbrielli [11] proposed a new design approach for a binary geothermal power plant at off-design conditions underlining the thermal degradation effect of geothermal brine re-injection process throughout the years on plant performance. In that study and several other studies [12-14], off-design isentropic turbine efficiencies are calculated with the correlation proposed originally by Keeley [15]. Jüdes et al. [16] implemented another empirical correlation to model the part-load behaviour of a steam turbine in a cogeneration (CHP) plant. In another study, Fiaschi et al. [17] elaborated design of light-duty radial turbines and proposed a 0-D model for design of the ORC turbines. Proposed model is also employed for the prediction of off-design turbine performance by modelling of turbine curves. Dawo et al. [18] compared different turbine curve modelling approaches in order to validate and simulate part-load performance of an existing Kalina cycle power plant from Unterhaching/Germany.

The aim of this paper is to model ORC turbine curves sourced by an existing geothermal source at off-design conditions under part-load. A thermodynamic model and statistical model will be constructed with the help of two-cycle plant data. Utilizing statistical analysis tools such as maximum likelihood estimation and probability distribution, plant variables such as reduced mass flow rates of working fluid or pressure ratios at turbines will be obtained for Stodola curve modelling purposes. With the help of this data, turbine characteristics (i.e. number of stages) and curves will be obtained for both cycles and results will be compared with proposed correlations from literature -namely Gabbrielli [11] and Jüdes [16] -. The novelty of this study lies within the existence of actual design and offdesign plant data from southwestern Anatolia and their utilization for part-load modelling of ORC turbines. Outputs of this study -i.e. turbine curve modelling and validation- will be the prologue of a plant optimization, which is planned as a further research topic. 


\section{Material and Methods}

Fig.1 depicts the plant layout modelled in UNISIM software. Consisting of two separate ORC systems, the nominal capacity of the binary geothermal plant is around $22.5 \mathrm{MW}$. Cycle-I differs from Cycle-II by having an extra top-preheater which is utilized for further heating of common working fluid n-pentane:

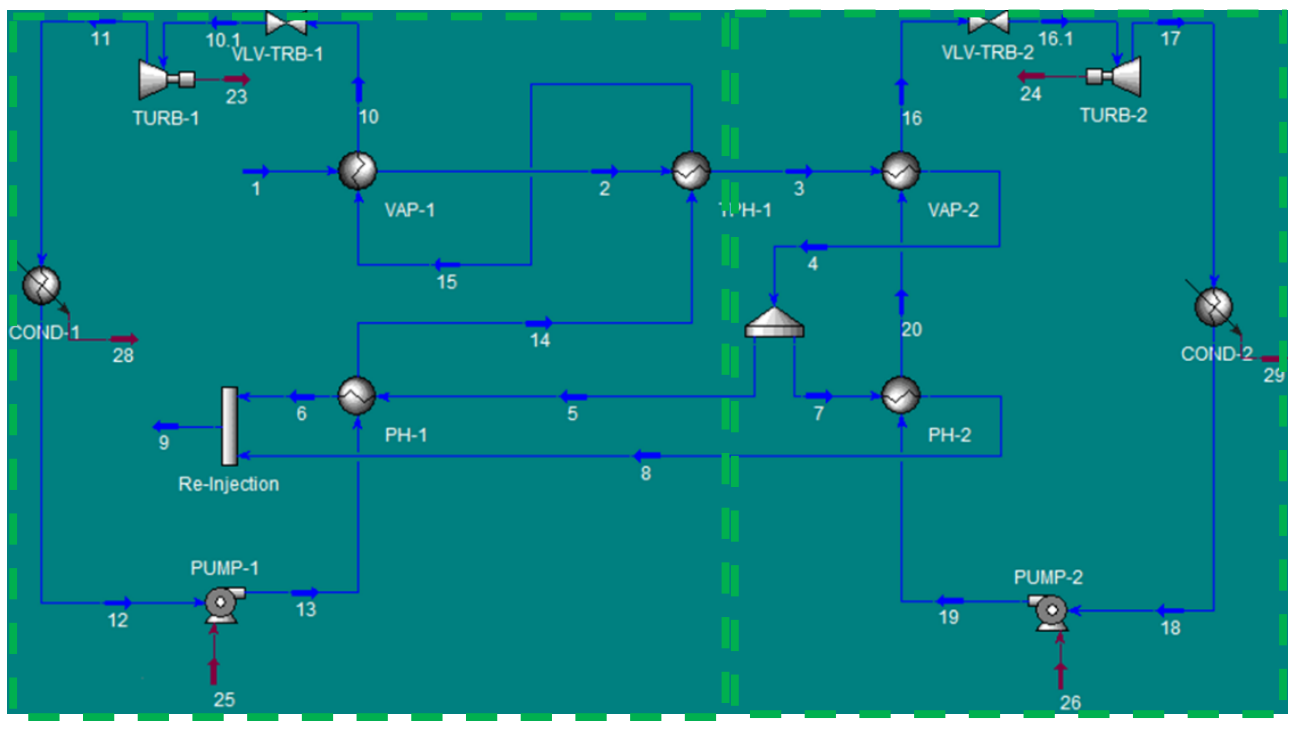

Fig.1: Plant Layout in UNISIM

\subsection{Brief Description of the Plant and Physical Assumptions}

As depicted in the Fig.1, brine is extracted from the wells and sent to the Vaporizer-I where it transfers its enthalpy initially to the n-pentane in Cycle-I. Afterwards brine continues to transfer energy to both cycles until it gets re-injected (see brine line between 1-9). Cycle-I operating with an extra internal heat exchanger (top-preheater) extracts more energy from the geothermal source, while Cycle-II works at relatively lower pressure and temperature points. Consequently, work output of Turbine-I is relatively higher than Turbine-II.

The plant has been modelled in UNISIM software based on following physical assumptions:

-Steady-state conditions are assumed.

-Pipe pressure drops are neglected, thermal losses from heat exchangers or environments to the environment are not taken into the consideration.

-Non-condensable gases (NCG) are not taken into the account. 
-Pressure drop at the turbine stages is assumed to be independent from the number of stages [10].

- Thermodynamic properties of n-pentane are calculated using the Soave-Redlich-Kwong (SRK) [19] equation of state.

- Geothermal brine is modelled as standard water and equation provided by the International Association for the Properties of Water and Steam (IAPWS-95) [20] is utilized.

Various off-design datasets are utilized with different ambient temperatures throughout the different seasons of the years for modelling purposes. Utilized data are not measured in a controlled environment, as they are the output of the SCADA control system of the plant, hence their uncertainties are mainly unknown. Uncertainties have been considered as $1{ }^{\circ} \mathrm{C}$ for thermocouples, $1 \mathrm{~kg} / \mathrm{s}$ for flowmeters and 0.1 bar for pressure gauges.

\subsection{Theoretical Framework of the Turbine Correlations}

Since steam turbines are the subject of attention in this study, it is necessary to elaborate law of ellipse (or cone law) in detail. Stodola's cone approach proposes a methodology for prediction of turbine outlet pressure under non-choking flow conditions [10].

After empirical studies, Stodola described the relationship between the mass flow rate, temperature and pressure as a conic surface on Cartesian system and established a relationship between design and off-design conditions utilizing these parameters. Mathematical expression of flow ratio can be expressed as follows (acc. Stodola's ellipse):

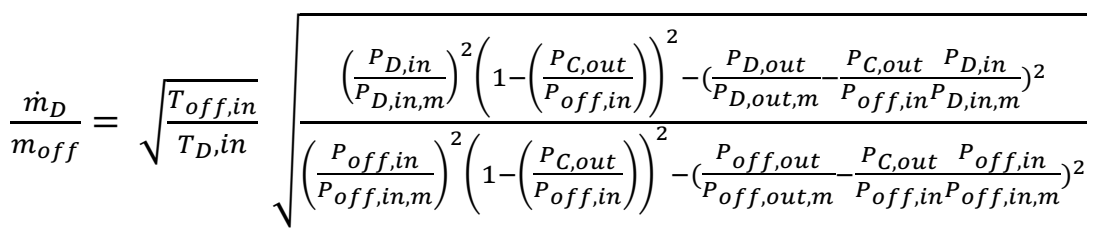

$D$ and off represent design and off-design conditions in that equation while in and out refers to inlet and outlet conditions. $m$ stands for maximum, $C$ is the subscript of term critical. It is possible to start the simplification of this equation by assuming a condensing turbine instead of backpressure turbine. By this means, outlet critical pressure becomes negligible; if the difference between inlet and outlet temperatures are insignificant for design and off design cases, temperature related term would also vanish. Maximum pressures for design and offdesign conditions at the inlet and outlet are also identical terms, hence these terms would cancel each other.

Off-design inlet pressure can be expressed as follows in final form:

$P_{o f f, \text { in }}=\sqrt{\dot{m}_{o f f}^{2} T_{o f f, \text { in }} Y_{D}-\left(\frac{\dot{m}_{o f f}}{\dot{m}_{D}}\right)^{2}+P_{o f f, o u t}}$ 
Where $Y_{D}$ is Stodola constant [10]:

$Y_{D}=\frac{P_{o f f, i^{2}}{ }^{2}-p_{D, o u t}{ }^{2}}{P_{o f f, i n}{ }^{2} \dot{m}_{D}{ }^{2}}$

In real operating conditions, a vast majority of the turbines work under choked flow conditions. Choking flow is associated with reduced mass flow rate rather than bulk mass flow rate as follows:

$\Phi=\frac{\dot{m}_{o f f}}{\sqrt{p_{o f f, i n} \rho_{\text {off }, \text { in }}}}$

When the flow gets choked, reduced mass flow rate reaches its maximum value. In other words, changes in pressure ratio have no effect on the reduced mass flow rate from the choking point on -i.e. Stodola curve becomes steeper-. Note that eq. (2) is valid for a single stage turbine. As aforementioned, it is assumed that the multi-stage turbine is designed in a manner that ensures same pressure ratio in each stage. Accordingly, the pressure ratio on a stage can be defined as:

$p_{r, s t}=p_{r}^{1 / n}$

Where $p_{r}$ represents the overall pressure ratio and $\mathrm{n}$ stands for the number of stages. Overall pressure ratio is known for both turbines at each different dataset utilized. By a reverse engineering approach, following equation is utilized to calculate the value of $Y_{d}$ for each turbine depending on the expected number of stages [10]:

$Y_{D}=\frac{\left(p_{r}^{1 / n}\right)^{2}-1}{\left(\Phi_{i n}\left(p_{r}^{1 / n}\right)\right)^{2}}$

Theoretical turbine isentropic efficiency is the ratio of irreversible enthalpy transfer to the reversible (or isentropic) enthalpy transfer formulated as follows [21] (acc. stream numbers in Fig.1 for Turbine-1):

$$
\eta_{s, T}=\frac{h_{10.1}-h_{11}}{h_{10.1}-h_{11, s}}
$$

Due to the thermal losses from turbines, a direct calculation of the efficiency based on the thermocouple data would lead an overestimation of the efficiency. To improve the accuracy of turbine efficiency calculations, thermal losses from the turbines to the environment will be estimated according to following formula:

$$
W_{L}=\left(T L C+T L C_{Q m o d} *(Q-1)\right) * \Delta_{\text {Tamb-Tinlet }}
$$


where TLC is the abbreviation of thermal loss coefficient, $T L C_{Q m o d}$ is the correcting factor if vapour quality drops below 1 and $\Delta_{\text {Tamb-Tinlet }}$ is the temperature difference between the environment and turbine inlet.

Gabbrielli [11] re-mentioned a former correlation in his work for direct estimation of ORC turbine isentropic efficiency in a binary geothermal plant:

$\eta_{o f f, s, T}=\eta_{D, s, T} \sin \left[0.5 \Pi\left(\frac{\dot{m}_{w f, o f f, i n}}{\dot{m}_{w f, D, i n}} \frac{\rho_{w f, D, i n}}{\rho_{w f, o f f, i n}}\right)^{0.1}\right]$

Where $w f$ is an abbreviation for the working fluid. This correlation simply associates offdesign mass flow rate change of the working fluid with density changes at the turbine inlet conditions. Jüdes et al. [16] proposed another empirical correlation which is more sensitive to mass flow rate changes at off-design conditions:

$$
\begin{aligned}
& \eta_{o f f, s, T}=\eta_{D, s, T}\left[-1.0176\left(\frac{m_{\text {off }}}{m_{D}}\right)^{4}+2.4443\left(\frac{m_{\text {off }}}{m_{D}}\right)^{3}-2.1812\left(\frac{m_{\text {off }}}{m_{D}}\right)^{2}+\right. \\
& 1.0535\left(\frac{m_{\text {off }}}{m_{D}}\right)+0.701
\end{aligned}
$$

Outputs from thermodynamic model of the plant will be validated with the help of turbine efficiency and outlet pressure correlations elaborated previously.

\subsection{Statistical Model}

Existing datasets are unfortunately not usable for direct validation purposes. Some vital information are missing, the most critical of which is the ORC mass flow rates in both cycles. Despite that, such values can be derived from the existing datasets and Table-1 summarizes missing critical values and utilized methodologies to calculate them.

Table-1: Calculation Methodologies of Missing Variables

\begin{tabular}{|l|l|l|}
\hline Variable & Description & Methodology \\
\hline$\dot{m}_{\text {ORC }-1}$ & Flow rate of ORC cycle 1 & Energy balance in $T P H-1$ \\
\hline$\dot{m}_{O R C-2}$ & Flow rate of ORC cycle 2 & Energy balance in $\mathrm{PH}-2$ \\
\hline$\dot{m}_{\text {ratio }}$ & $\begin{array}{l}\text { Brine mass flow distribution } \\
\text { rate between the cycles (i.e. } \\
\text { in Splitter) }\end{array}$ & Energy balance in $\mathrm{TPH}-1$ \\
\hline
\end{tabular}




\begin{tabular}{|l|l|l|}
\hline$T_{19}$ & $\begin{array}{l}\text { PH-2 working fluid inlet } \\
\text { temperature }\end{array}$ & $\begin{array}{l}\text { Evaluation of thermal resistance of pipes } \\
\text { between points } 12 \text { and } 13 \text { in Cycle-1 with } \\
\text { existing data such as } T_{12}, T_{13} \text { and } T_{\text {amb }} \cdot \\
\text { Assuming that the thermal resistance of } \\
\text { pipes in } \text { Cycle-2 is the same, } T_{19} \text { can be } \\
\text { obtained from } T_{18} \text { and } T_{\text {amb }} .\end{array}$ \\
\hline
\end{tabular}

As one can clearly extract from Figure-2, such a calculation would result in a huge uncertainty on the outputs, due to the propagation of the small uncertainties which are naturally connected with the data acquisition process. Therefore, a statistical method has been developed to improve the accuracy of model predictions. Distribution shown in Figure-2 has been calculated using a Monte Carlo methodology as described Figure-3. Random uncertainties are generated considering a normal distribution around plant data.

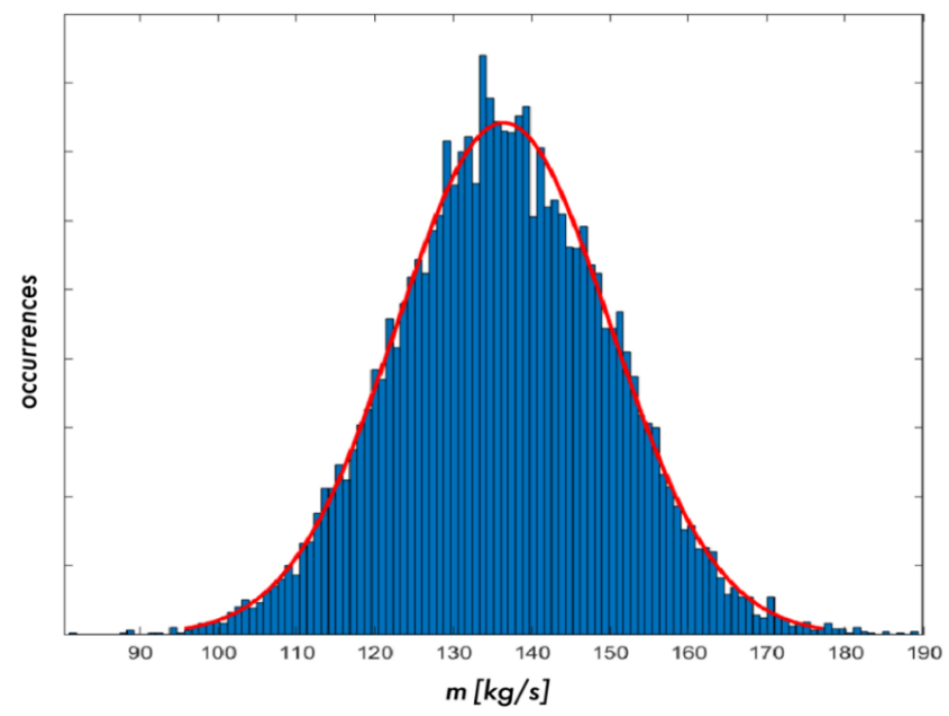

Fig.2: Probability Distribution of $\dot{\mathrm{m}}_{\mathrm{ORC}-1}$ for a Specific Dataset 


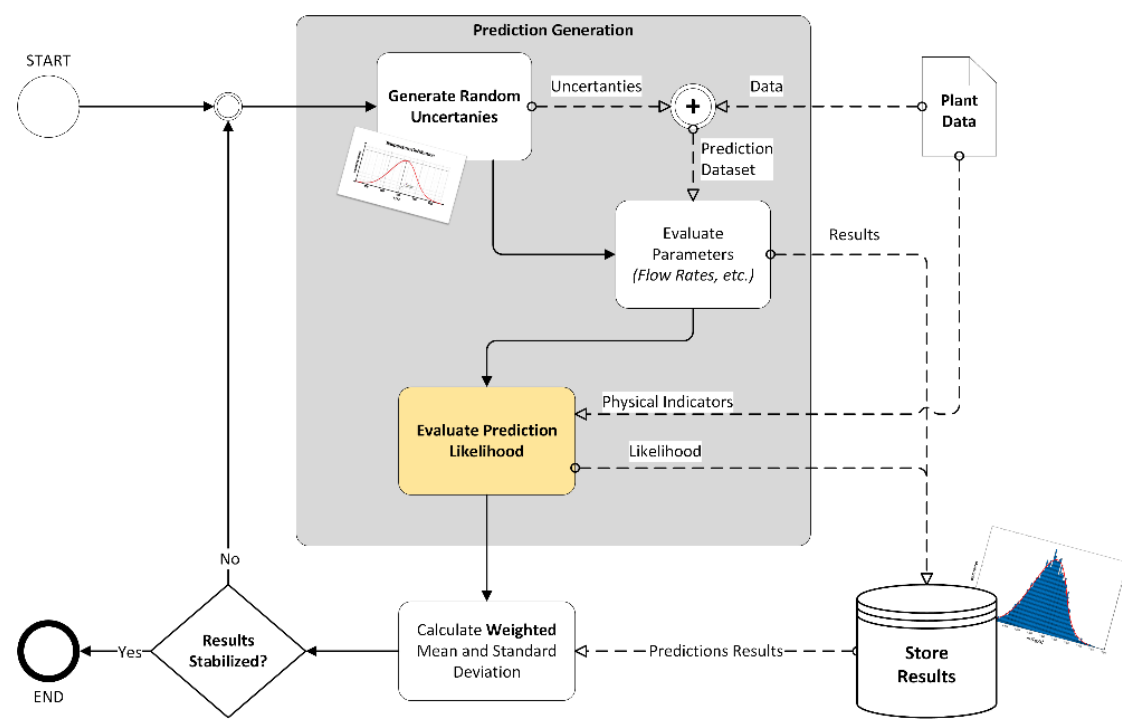

Fig.3: Statistical Analysis Scheme

\subsubsection{Maximum Likelihood Estimation}

Maximum likelihood estimation (MLE) is a statistical approach for predicting the parameters of a probability distribution by maximizing a certain likelihood function, intending to make the observed data most likely under the assumed statistical model [22]. Data distribution in Figure- 2 is obtained by evaluating $\dot{m}_{O R C-1}$ over different predictions generated by adding small random variations to the input variables. A trivial outcome from the Figure- 2 shall be that different predictions do not have the same possibility to be correct. Figure-4 clearly underlines this fact: Since obtaining a negative work output from a power plant is an impossible physical phenomenon, it is mandatory to exclude such points from the probability distribution.

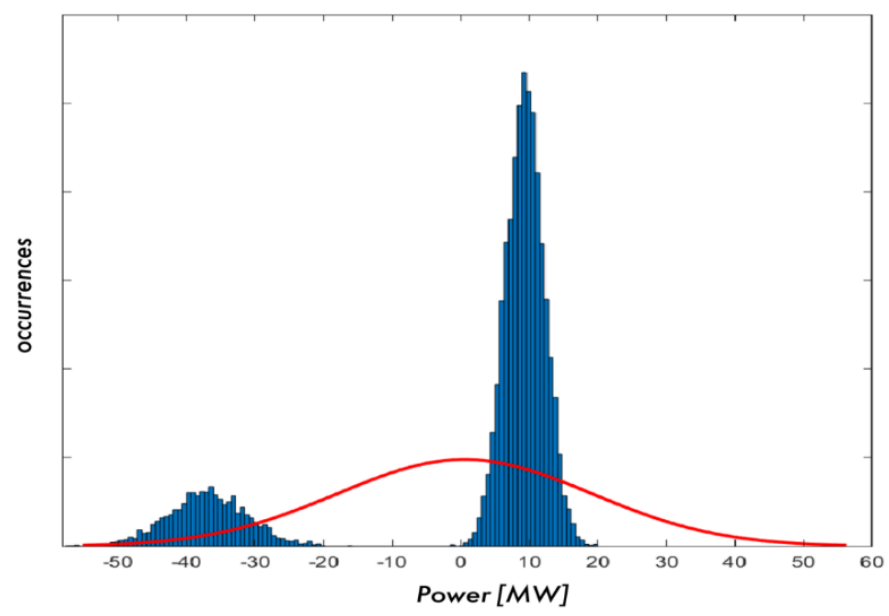

Fig.4: Probability distribution of $W_{\text {net }}$ 
By such an approach, it is possible to reduce the uncertainties to a certain extent. A feasible way of excluding physically unfeasible points is to consider the weighted mean and standard deviation of the predictions result over the likelihood of each prediction $\left(l h_{i}\right)$ :

$$
\text { mean }=\frac{\sum \text { value }_{i} l h_{i}}{\sum l h_{i}}
$$

To evaluate the likelihood of a specific prediction, some points from the datasets -like vaporizer outlet temperature- are utilized as physical indicators since they represent the outputs of off-design model. These indicators are employed in a manner that determines the likelihood of the occurrence of such a case in a physical environment under assumed conditions. Table- 2 provides the physical indicators employed in the off-design model:

Table-2: Physical Indicators in the Off-Design Model

\begin{tabular}{|l|l|l|}
\hline Indicator & Description & Cycle \\
\hline$T_{10}$ & Temperature Outlet - Vaporizer & Cycle 1 \\
\hline$\eta_{T U R B 1}$ & Turbine Isentropic Efficiency & Cycle 1 \\
\hline$Q_{12}$ & Vapour Quality Outlet - Condenser & Cycle 1 \\
\hline$T_{16}$ & Temperature Outlet - Vaporizer & Cycle 2 \\
\hline$\eta_{T U R B} 2$ & Turbine Isentropic Efficiency & Cycle 2 \\
\hline$Q_{18}$ & Vapour Quality Outlet - Condenser & Cycle 2 \\
\hline
\end{tabular}

The overall likelihood of the $i$-th condition is the product of the likelihoods evaluated for each $(j-t h)$ additional information:

$$
l h_{i}=\prod_{j} l h_{i j}
$$

Different methods are applied depending on the type of variable to be predicted: 
Temperature: Knowing that temperature is calculated by the model for a specific point $\left(T_{\text {eval }}\right)$ and the actual temperature measured in the plant in that condition $\left(T_{\text {mea }}\right)$, maximum likelihood is expected to occur when $T_{\text {eval }}$ equals the $T_{m e a}$. It is possible to evaluate such a probability like an area under the curve depicted in Figure-5.

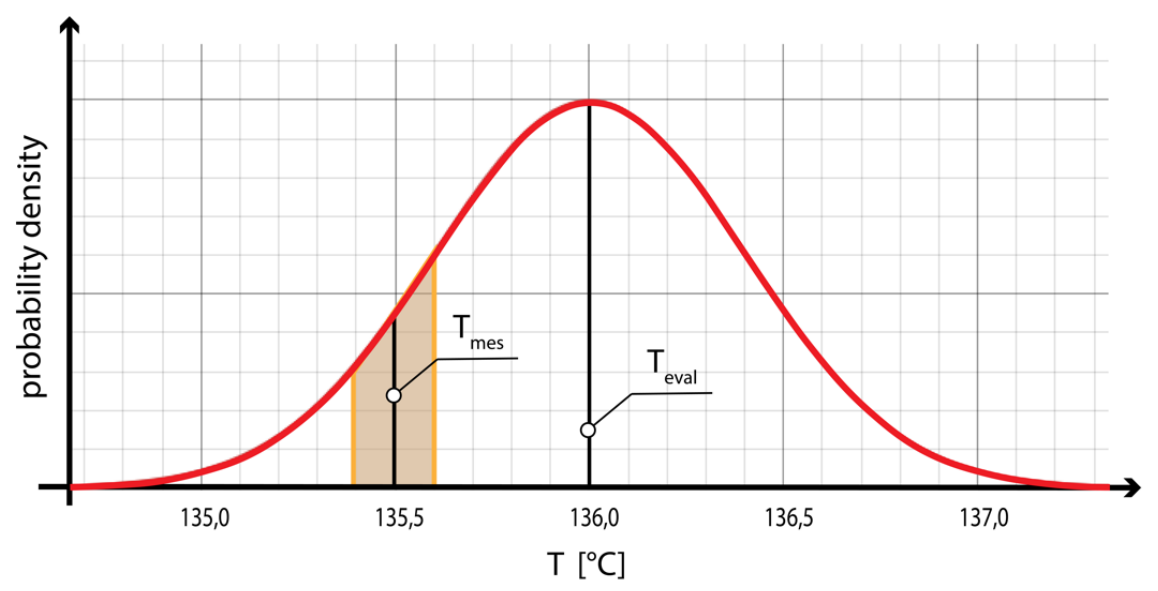

Fig.5: Likelihood of temperature distribution (Gaussian)

If a Gaussian distribution is assumed for the measured values, the mean value would be the actual temperature of the fluid. Hence the likelihood can be calculated using the following formula:

$l h_{i j}=c d f\left(T_{m e s}+\frac{\Delta T_{d e c}}{2}, T_{e v a l}, \sigma_{T C}\right)-c d f\left(T_{m e s}-\frac{\Delta T_{d e c}}{2}, T_{e v a l}, \sigma_{T C}\right)$

Where $c d f(x, \mu, \sigma)$ is the cumulative function, i.e. the integral of a Gaussian distribution:

$c d f(x, \mu, \sigma)=\frac{1}{2}\left(1+\operatorname{erf}\left(\frac{\mu-x}{\sqrt{2 \sigma}}\right)\right)$ with $\operatorname{erf}(x)=\frac{2}{\pi} \int_{0}^{x} e^{-t^{2}} d t$

$\Delta T_{\text {dec }}$ is the maximum interval that can be added to $T_{m e s}$ without changing the displayed number. For instance, if the temperature value is displayed with only one decimal point, temperatures like 135.34 and 135.29 will be both displayed as 135.3 , hence $\Delta T_{\text {dec }}$ would be 0.1 in this case.

Efficiency: As it is expected to reach a value of the isentropic efficiency around 0.8 , efficiencies much higher and lower than this value are considered to be less likely. The likelihood can be evaluated using the following equation, which is depicted in Figure-6.

$$
l h_{i j}=\frac{1}{1+e^{12-25 \eta}} \cdot\left(1-\frac{1}{1+e^{34-28 \eta}}\right)
$$




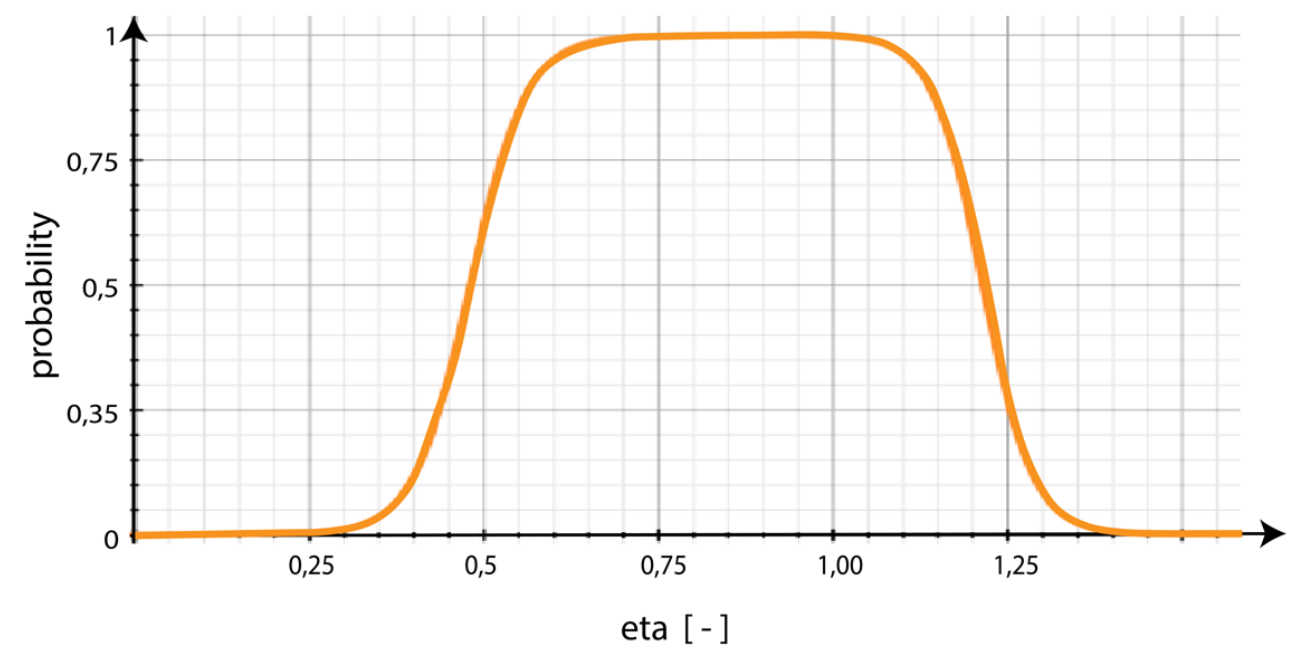

Fig.6: Likelihood of isentropic efficiency distribution

Fig.6 depicts initial probability estimations for turbine efficiencies: these values are "initial" as the term implies; nevertheless, it is empirically known that it is necessary to exclude the cases in which turbine efficiencies are lower than 0.5 and higher than 1.10. Values between 1-1.10 are also taken into the account owing to the fact that some thermal losses are expected from the turbine and its surroundings.

Vapor Quality: Since the vapor presence at condenser outlet is always avoided to protect the mechanical structure of the pump in practical applications, a prediction in which vapor quality at the condenser outlet takes a value other than zero is rejected. Hence:

$$
l h_{i j}= \begin{cases}1, & Q=0 \\ 0, & Q \neq 0\end{cases}
$$

The likelihood of any other variable can be estimated utilizing other physical constraints.

\subsubsection{Curve Fitting}

The methodology so far described aimed to reduce uncertainties in the off-design model and to focus on the conditions that are more likely to be physically correct. Nevertheless, a certain amount of uncertainty would still be present in the calculated values. Due to this reason, this methodology will be extended to turbine curve fitting purposes as well.

Curve fitting can be simply described as fitting the best mathematical expression to a certain dataset using different techniques such as interpolation. In this case, the dataset will be the off-design plant data which is previously processed employing likelihood of occurrence as described in previous section. 
As explained in earlier sections, it is possible to estimate the occurrence of the datapoints in frame of the relationship between probability and likelihood. Similarly, it may also be possible to fit the most probable curve into these datapoints by maximizing the likelihood. In order to estimate the most probable curve, one can propose that the overall probability for the $i$-th curve $\left(p_{c_{i}}\right)$ is the mean average of the $j$-th datapoints:

$p_{c_{i}}=\frac{\sum_{j} p_{c i j}}{n}$

Gaussian distribution is assumed for the evaluation of $p_{c_{i j}}$ as explained previously:

$p_{c_{i j}}=p d f\left(x_{c_{i j}}, x_{\exp _{j}}, \sigma_{j}\right)$

where $x_{\text {exp }}$ is the position of the $\mathrm{j}$-th experimental point, $x_{c_{i j}}$ is the position of the $\mathrm{j}$-th experimental point as evaluated by the i-th curve, $\sigma_{j}$ is the estimated standard deviation for the $\mathrm{j}$-th point and $p d f(x, \mu, \sigma)$ is the probability density function for the normal (i.e. Gaussian) distribution. Note that $x_{\exp }$ and $\sigma_{j}$ are the weighted mean of the $\mathrm{j}$-th dataset calculated according to the procedure described in Figure-3.

Figures 7 and 8 aim to explain this interpolation methodology visually:

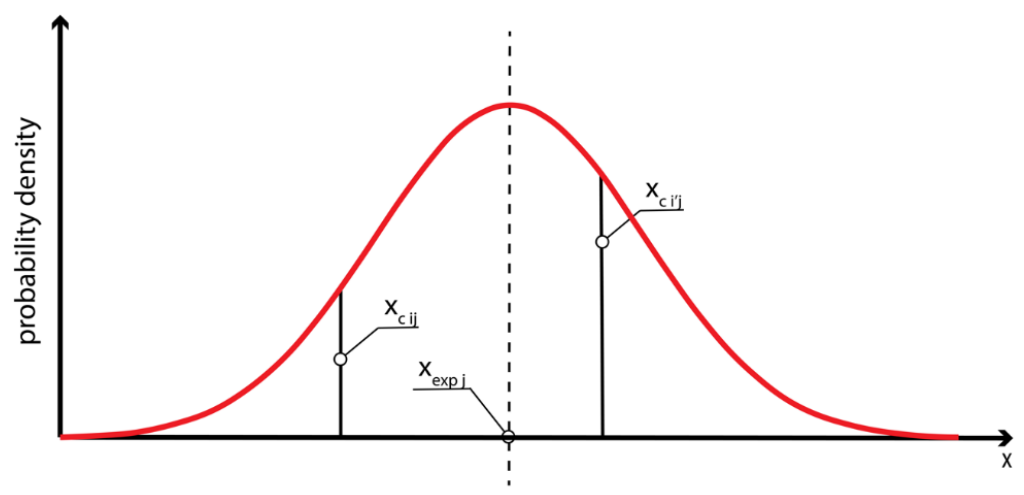

Fig.7: Curve likelihood calculation of a single datapoint

In the Figure 7, intersections of the two curves $i$ and $i^{\prime}$ are depicted. Notice that the curve $i^{\prime}$ is more likely to be correct than $i$ because its prediction $x_{c_{i j}}$ is closer to $x_{\exp _{j}}$. Or in other words $x_{c i{ }^{\prime} j}$ has a higher probability density than $x_{c_{i j}}$. 


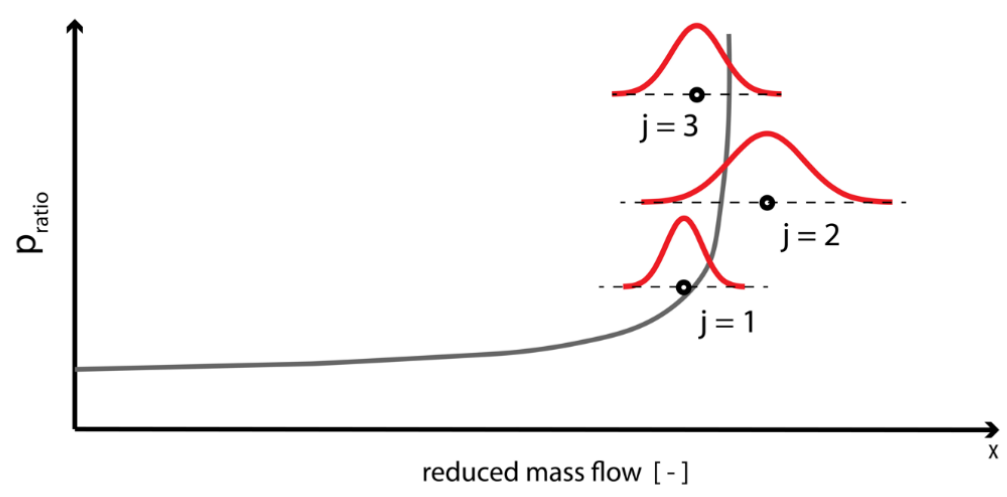

Fig.8: An application of likelihood approach on Stodola curve

The overall probability of the curve can be estimated according to Eqns. (16) and (17) by taking the mean average of probability density of each single datapoint considering their standard deviations as shown in Fig.8. This approach can be applied to any curve-fitting problem.

\section{Results and Discussion}

In this section, estimations regarding turbine characteristics such as the number of stages and turbine curves will be presented. Afterwards, turbine isentropic efficiency calculations will be compared with Gabbrielli and Jüdes correlations for further validation purposes. The relationship between ambient temperature and thermal losses will be discussed as well.

Fig. 9 shows the probability of turbine number of stages based on Stodola equation. Both turbines are expected to be two-stage turbines [23] in real-operation conditions since they are the expanders operating with n-pentane, accordingly Fig. 9 demonstrates that the projected thermodynamic and statistical models represent valid results in terms of turbine characteristics -especially for Turbine-I-: 


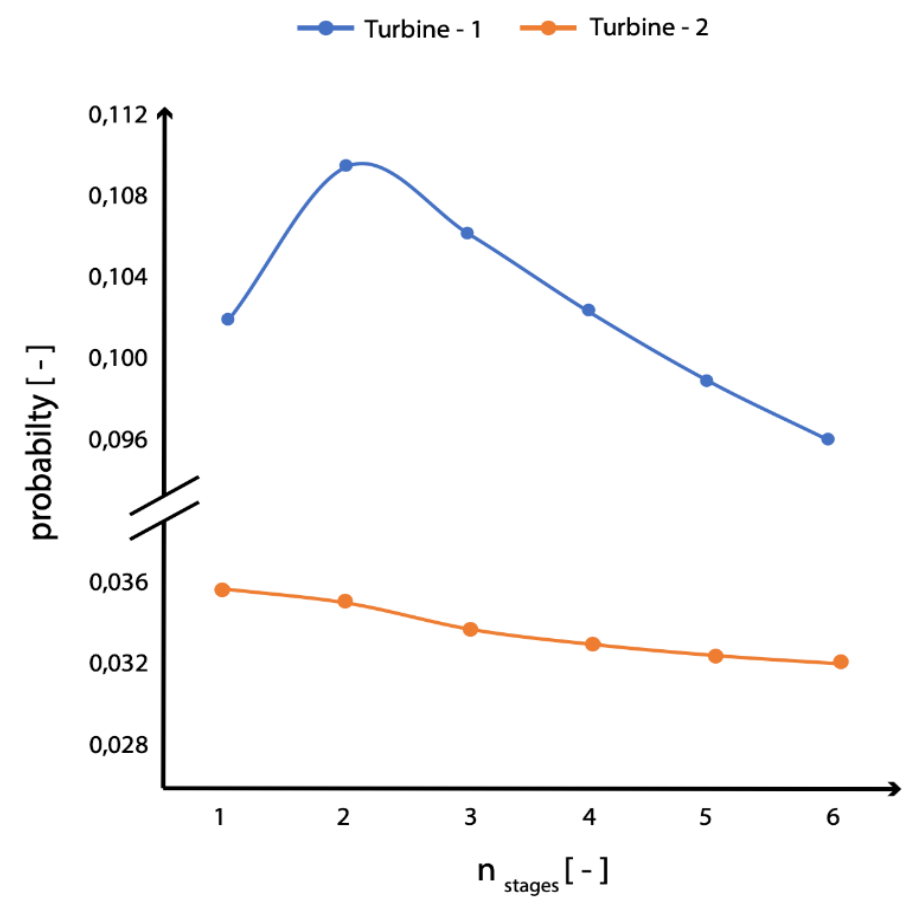

Fig.9: Probability of Turbine Number of Stages

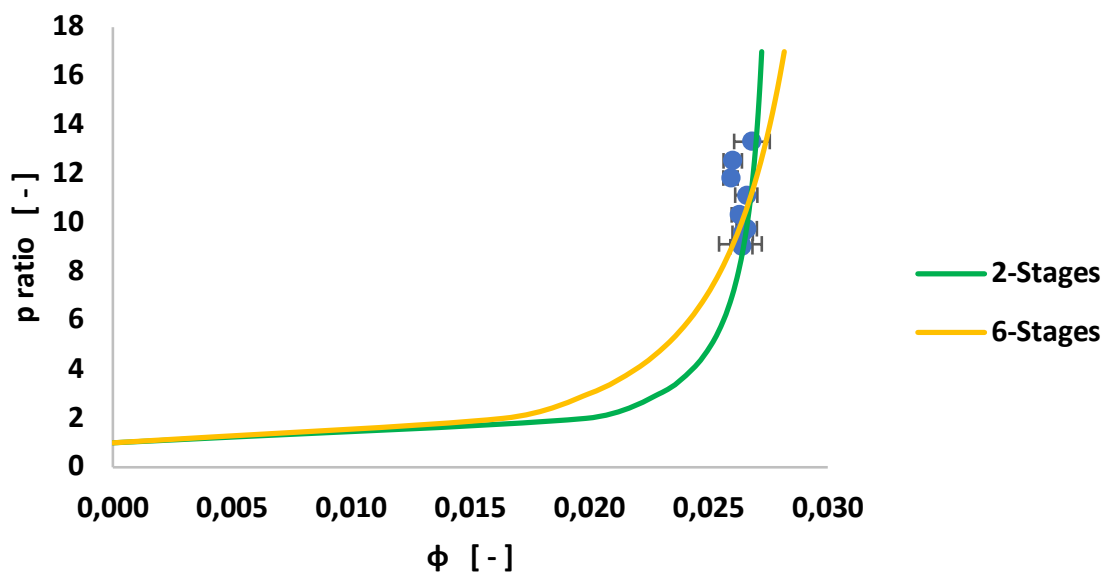

Fig.10: Stodola Curves for Turbine-I

Figure-10 depicts the Stodola curves for 6-Stage and 2-Stage turbine variants in terms of $\Phi$ (reduced mass flow rate) and pressure ratio (p_ratio). These two stage variants are presented due to the fact they represent the highest and lowest possibilities (see Figure-9). 
As one can extract from the Figure-10, a 2-stage turbine model fits more accurately to the calculated off-design datapoints (in their standard deviations) based on existing plant datasets.

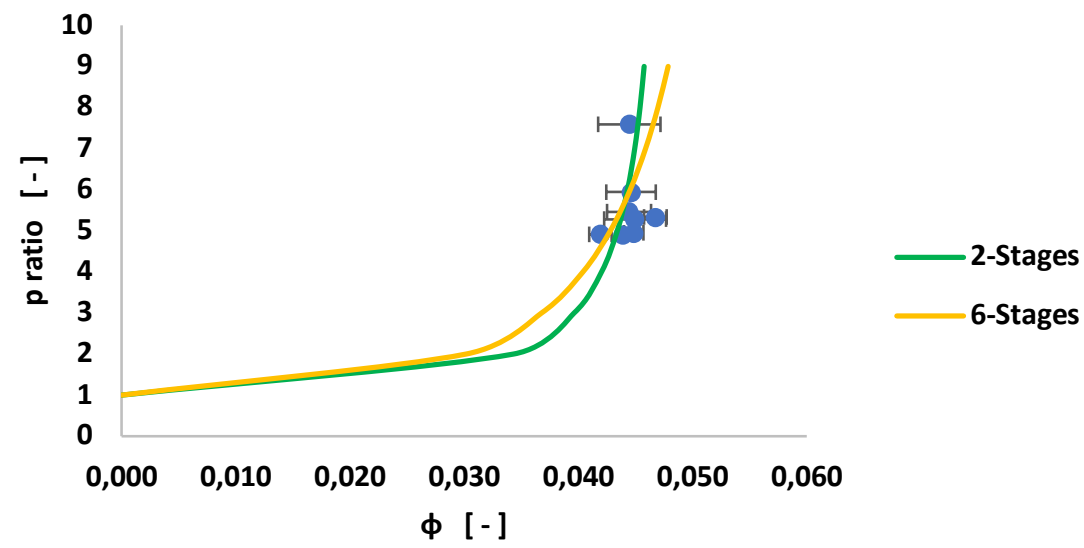

Fig.11: Stodola Curves for Turbine-II

In Figure-11, Stodola Curves for Turbine-II are depicted. As for Turbine-I, a 2-Stage turbine model fits better to the calculated datapoints from thermodynamic and statistical models. Turbine isentropic efficiency values are also estimated with the help of constructed models.

In real cases there are some losses from the turbines to the environment which are related with thermal losses to the environment, mechanical irreversibilities and electrical conversion inefficiencies.

Figure-12 shows the gross work outputs estimated with the help of constructed models taking turbine losses (thermal losses as defined in eq. (7), mechanical losses and electrical conversion losses) into the account - against real dataset gross work outputs. Table-3 provides the parameters calculated for the estimation of thermal losses:

Table-3: Thermal losses coefficients calculated by the model

\begin{tabular}{|r|r|r|}
\hline TLC & 3 & {$[\mathrm{~kW} / \mathrm{K}]$} \\
\hline TLC $_{\text {Q mod }}$ & -48 & {$[\mathrm{~kW} / \mathrm{K}]$} \\
\hline
\end{tabular}




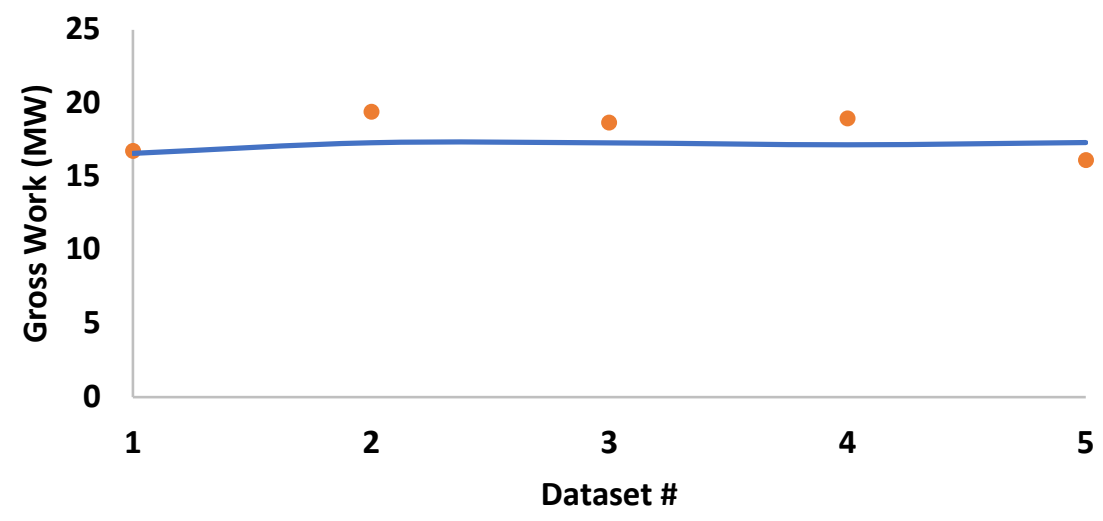

- Datapoints Estimations

Fig.12: Gross work output: Existing data vs. Estimations

Taking turbine loss estimations into the account, results show a decreasing trend of overall efficiencies for both turbines with increasing reduced mass flow rates. From another point of view, one can also state that overall turbine efficiencies fluctuate around their design efficiencies. Gabbrielli and Jüdes correlations also estimate fixed efficiency values around 0.84 and 0.77 respectively for Turbine-I and II.

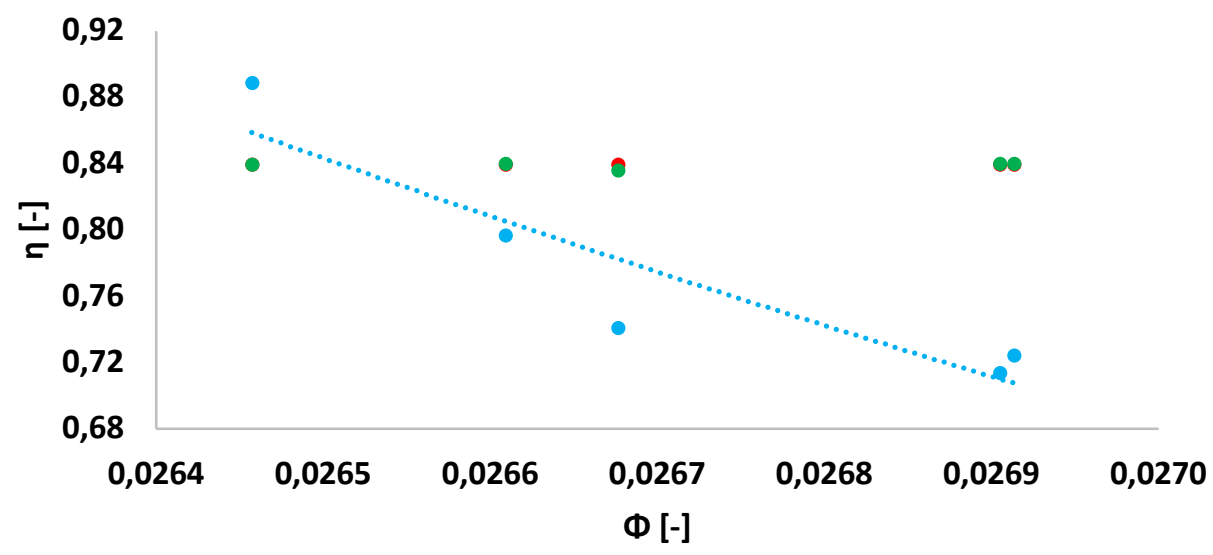

- Turbine-I • Gabbrielli • Jüdes

Fig.13: Turbine-I Overall Efficiencies vs. Correlation Efficiencies

After the extraction of overall losses (thermal-mechanical-electrical), overall efficiency of Turbine-I shows a decreasing trend with increasing reduced mass flow rate. This may be associated with the increased choking of the turbine. Correlations estimate a rather fixed isentropic efficiency for off-design conditions; that is an expected outcome since these correlations are influenced mainly by the design efficiency, which is a constant value. On the other hand, these correlations are proposed for non-choking conditions which is invalid for off-design conditions of ORC turbines. 


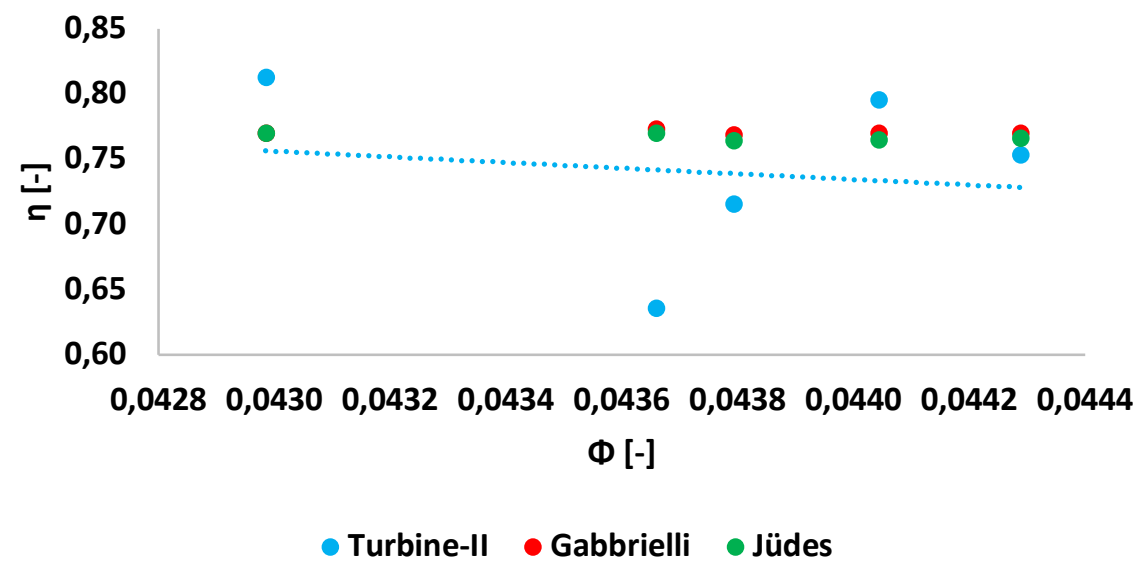

Fig.14: Turbine-II Overall Efficiencies vs. Correlation Efficiencies

Fig.14 replicates the reverse trend between turbine efficiency and reduced mass flow rate. Value pairs are a little bit more loosely dispersed throughout the different points in TurbineII, this may be a subject of attention for further studies. 


\section{Conclusions}

In this study, off-design modelling of ORC turbines is aimed. With the help of off-design datasets from different seasons of different years, thermodynamic and statistical models are constructed under part-load conditions. Turbine characteristics such as number of stages and Stodola curves are determined. Thermal losses from the turbines are associated with ambient temperatures as well as the association of mechanical and electrical conversion losses with mechanical and electrical conversion inefficiencies. Obtained overall turbine efficiency values are compared with the Gabbrielli and Jüdes correlations from the literature.

Main conclusions can be summarized as follows:

- Stodola curves and probability calculations demonstrate that both turbines are most likely to have 2 stages.

- Average losses are 2.3 MW and 1.2 MW from Turbine-I and Turbine-II respectively throughout the different seasons.

- After the extraction of losses, overall turbine efficiencies demonstrate a reverse trend with increasing reduced mass flow rate. This may be associated with the increased choking of the turbine.

- Correlations estimate rather fixed efficiency values at off-design conditions (84\% for Turbine-I and $77 \%$ for Turbine-II); that is an expected outcome since these correlations are influenced by the design isentropic efficiency, which is a constant value.

- On the other hand, these correlations are most likely to be proposed for non-choking conditions which are invalid for off-design conditions of existing ORC turbines.

- Datapoint dispersion in Turbine-II does not demonstrate a strong correlation with physical constraints such as -pressure ratio and reduced mass flow rate- as it does for Turbine-I; this phenomenon may need further attention for future work. 


\section{References}

[1] DiPippo R. (2016), 2: Developments and Innovation, Woodhead Publishing, https://doi.org/10.1016/C2014-0-03384-9.

[2] https://www.thinkgeoenergy.com/global-geothermal-capacity-reaches-14900-mw-newtop10-ranking/

[3] DiPippo R. (2015), Geothermal Power Plants Principles, Applications, Case Studies and Environmental Impact (4th edition), Butterworth-Heinemann, ISBN: 9780081002902.

[4] Kalina A.I. (2003), New Binary Geothermal Power System. International Geothermal Workshop, Geothermal Energy Society.

[5] Macchi E., Astolfi M., (2017) Organic Rankine Cycle (ORC) Power Systems: Technologies and Applications, Woodhead Publishing, ISBN: 978-0-08-100510-1.

[6] DiPippo, R. (2007). Ideal thermal efficiency for geothermal binary plants. Geothermics; 36: $276-285$.

[7] Aghahosseini S, Dincer I (2013). Comparative performance analysis of low temperature Organic Rankine Cycle (ORC) using pure and zeotropic working fluids, Applied Thermal Engineering; 54(1): 35-42.

[8] Basaran A., Ozgener L (2013)., Investigation of the effect of different refrigerants on performances of binary geothermal power plants. Energy Conversion and Management; 76: 483-498.

[9] Thurairaja K., Wijewardane A., Jayasekara S., Ranasinghe C. (2019), Working fluid selection and performance evaluation of ORC, Energy Procedia; 156: 244-248.

[10] Cooke D.H. (1985), On Prediction of Off-Design Multistage Turbine Pressures by Stodola's Ellipse, J. Eng. Gas Turbines Power; 107(3): 596-606.

[11] Gabbrielli R. (2012), A novel design approach for small scale low enthalpy binary geothermal power plants, Energy Conversion and Management; 64: 263-272.

[12] Calise F, Capuano D, Vanoli L. (2015) Dynamic simulation and exergo-economic optimization of a hybrid solar-geothermal cogeneration plant. Energies (8):2606-46.

[13] Wang J, Wang J, Dai Y, Zhao P. (2017), Assessment of off-design performance of a Kalina cycle driven by low-grade heat source. Energy; 138: 459-72. 
[14] Yoon SY, Kim MJ, Kim IS, Kim TS. (2017), Comparison of micro gas turbine heat recovery systems using ORC and trans-critical CO_2 cycle focusing in off-design performance. Energy Procedia;129: 987-94.

[15] Keeley KR. (1988) A theoretical investigation of the part-load characteristics of LP steam turbine stages. CEGB memorandum RD/L/ES0817/M88. Central Electrical Generating Board, UK.

[16] Jüdes M, Vigerske S, Tsatsaronis G. (2009) Optimization of the design and partial-load operation of power plants using mixed-integer nonlinear programming. In: Pardalos PM, Kallrath J, Rebennack S, Scheidt M, editors. Optimization in the energy industry. first ed. Springer-Verlag; p. 193-220.

[17] Fiaschi D., Manfrida G., Maraschiello F. (2015), Design and performance prediction of radial ORC turboexpanders, Applied Energy,138: 517-532.

[18] Dawo F., Wieland C., Spliethoff H., (2019) Kalina power plant part load modeling: Comparison of different approaches to model part load behavior and validation on real operating data, Energy; 174: 625-637,

[19] Murdock, James W. (1993), Fundamental fluid mechanics for the practicing engineer, CRC Press, pp. 25-27, ISBN 978-0-8247-8808-7.

[20] Pruss A, Wagner W., (2002), The IAPWS Formulation 1995 for the Thermodynamic Properties of Ordinary Water Substance for General and Scientific Use, Journal of Physical and Chemical Reference Data 31; 387, https://doi.org/10.1063/1.1461829.

[21] Dincer I, (2018), Comprehensive Energy Systems, Elsevier Inc., ISBN: 978-0-12814925-6.

[22] Rossi, R. J. (2018). Mathematical Statistics : An Introduction to Likelihood Based Inference. New York: John Wiley \& Sons. ISBN 978-1-118-77104-4.

[23] Meroni A., Andreasen J.G., Persico G., Haglind F. (2018), Optimization of organic Rankine cycle power systems considering multistage axial turbine design, Applied Energy; 209: 339-354. 